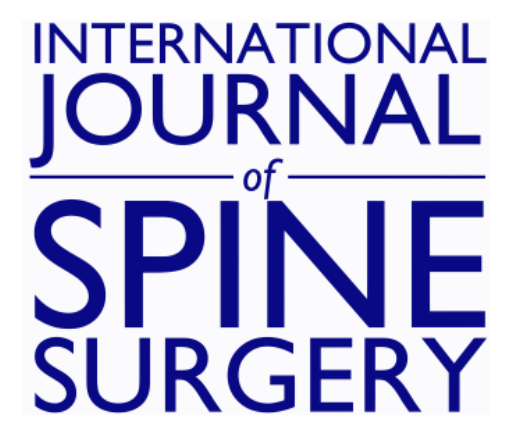

\title{
Thoracic disc herniation: An unusual complication after prone positioning in spinal surgery
}

Ameya S. Kamat, Mohammed Zahier Ebrahim and Adriaan J. Vlok

Int J Spine Surg 2016, 10 ()

doi: https://doi.org/10.14444/3039

http://ijssurgery.com/content/10/39

This information is current as of April 26, 2023.

Email Alerts Receive free email-alerts when new articles cite this article. Sign up at:

http://ijssurgery.com/alerts

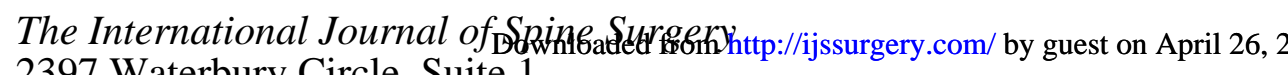
2397 Waterbury Circle, Suite 1,

Aurora, IL 60504, Phone: +1-630-375-1432

(C) 2016 ISASS. All Rights Reserved. 


\section{Thoracic disc herniation: An unusual complication after prone positioning in spinal surgery}

Ameya S. Kamat MBBCh., Mohammed Zahier Ebrahim MBChB., Adriaan J. Vlok FC Neurosurg (SA)

Division of Neurosurgery, Tygerberg Academic Hospital, Stellenbosch University, Cape Town, South Africa

\section{Abstract}

Neurological complications of the prone position have been well documented. Post-operative paraplegia and neurological deterioration unrelated to the site of surgery after proning in spinal surgery is a rare but potentially devastating complication. We describe the case of a 47 year old female who underwent an L4/5 discectomy and posterior instrumented fusion. A few hours after surgery she developed bilateral lower limb weakness with a T11 sensory level. Post-operative MRI revealed an acute disc herniation at the T11/12 level with associated spinal cord compression. This was not present on the pre-operative imaging. A subsequent T11/12 discectomy and instrumented fusion was performed and the patient's motor and sensory function returned to normal.

\section{Introduction}

Neurological complications of the prone position have been well documented. Post-operative paraplegia or neurological deterioration unrelated to the site of surgery after prone positioning in spinal surgery is a rare but potentially devastating complication. Ischemia and mechanical injury are the commonest causes and usually refer to the cervical spine and involve pre-existing pathology. ${ }^{1-3} \mathrm{We}$ describe a case of paraplegia due to acute herniation of the T11/12 intervertebral disc immediately after L4/5 discectomy and instrumented fusion.

\section{Case report}

A 47 year old female presented to our institute with a one month history of severe, debilitating lower back pain and radicular pain referring to her left $\mathrm{L} 4$ dermatome. She denied weakness and had no abnormal bladder or bowel symptoms. She had a positive smoking history of 10 cigarettes per day but no other medical co-morbidities.

Examination findings revealed a healthy looking female with a normal gait. The patient had reduced power in her left L4 and L5 myotomes, diminished sensation to light touch, pinprick and pressure in her left L4 dermatome but had normal knee and ankle reflexes bilaterally.
Plain film radiographs revealed a grade 1 degenerative spondylolisthesis of L4 on L5 and magnetic resonance imaging (MRI) demonstrated a central, left foraminal and lateral recess stenosis at the L4/5 level with compression of the L4 nerve root (Figure 1). The patient had an otherwise normal neurological examination with respects to the thoracic and cervical regions. After conservative care was exhausted, the patient was brought forward for a $\mathrm{L} 4 / 5$ discectomy and posterior instrumented fusion. The patient was placed on a Wilson Frame with their head positioned on the Mayfield Horseshoe. Surgery occurred approximately two weeks after the MRI scan had been performed. The procedure was uneventful and standard intravenous analgesics were utilized for pain control.

Post-surgical assessment in the recovery room revealed a pain free, comfortable patient. Although still slightly drowsy, examination revealed a proximal leg weakness bilaterally of $1 / 5$ and $2 / 5$ weakness in both feet. A sensory level at T11 was elucidated. She had a urinary catheter in situ which was functioning. These features were not present pre-operatively. An urgent MRI was performed which demonstrated an acute disc herniation at the T11/12 level with spinal cord compression and signal change within the spinal cord (Figure 2, Figure 3). This was not noted on the pre-operative MRI. 
Soon after the MRI, the patient was brought forward for an urgent T11/12 discectomy and instrumented fusion (Figure 4). The procedure was performed through a posterior approach and was uncomplicated. Post-operatively the patient's motor and sensory function returned to normal within 24 hours with complete resolution of her initial L4 pain as well.

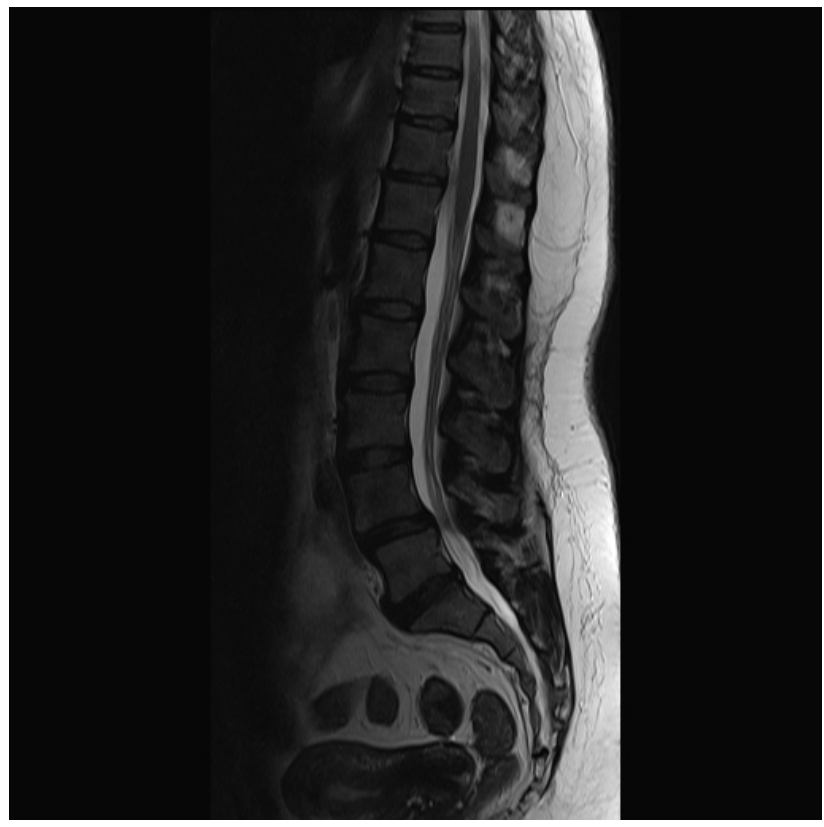

Fig. 1. Pre-operative T2-weighted saggital MRI demonstrating disc prolapse at L4/5. Note, there is no disc prolapse at T11/12.

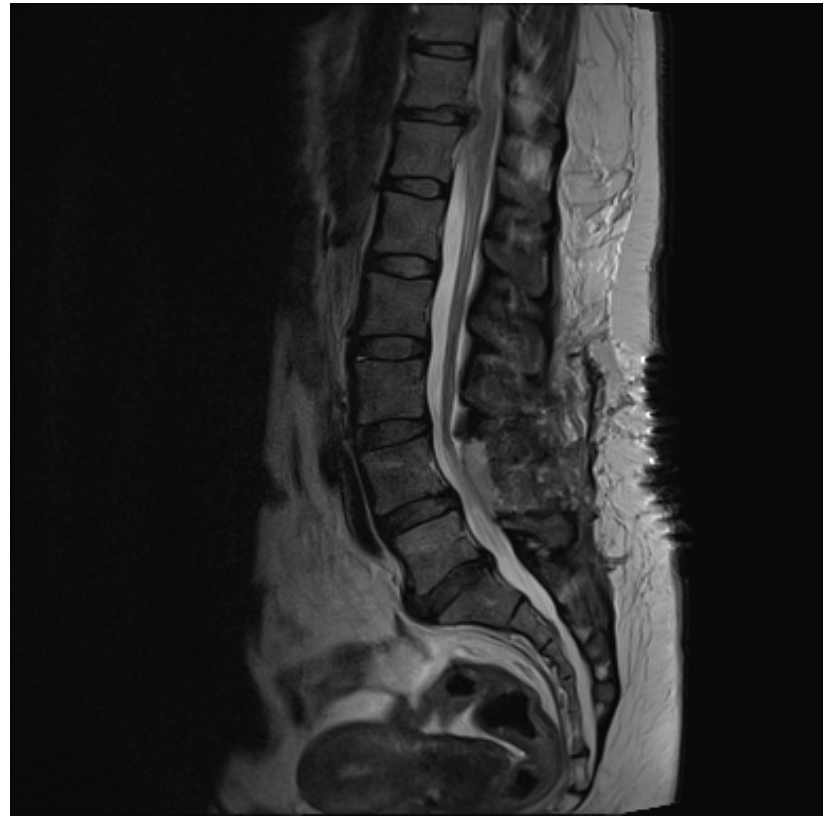

Fig. 2. Post-operative T2-weighted saggital MRI demonstrating disc prolapse at T11/12.

\section{Discussion}

Several complications have been implicated with the prone position. The risks are present both during the action of proning as well as the final prone position. The action of proning occurs most commonly while

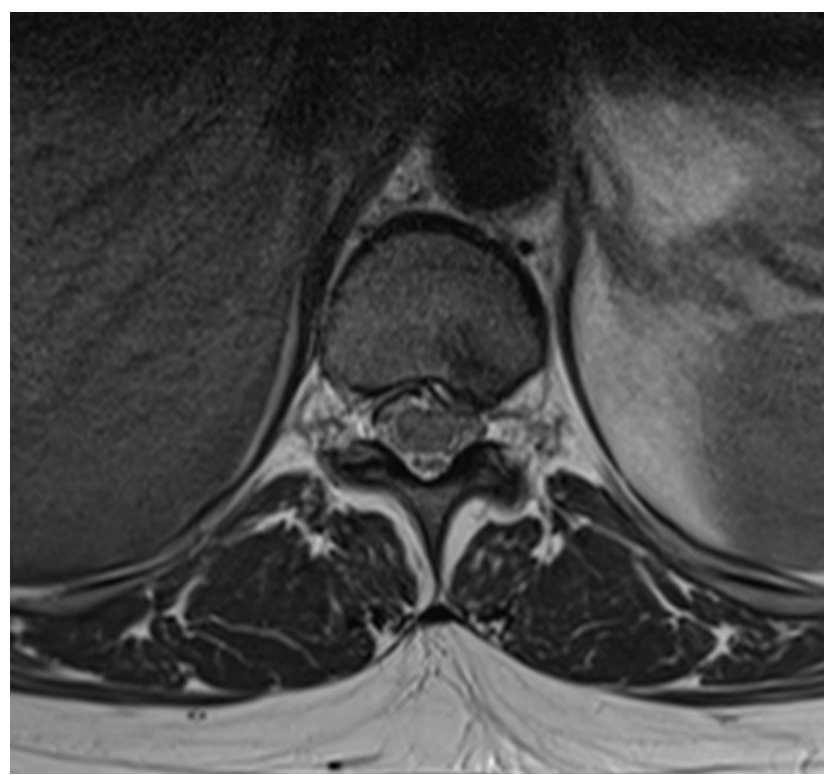

Fig. 3. Post-operative T2-weighted axial MRI demonstrating disc prolapse at $\mathrm{T} 11 / 12$.

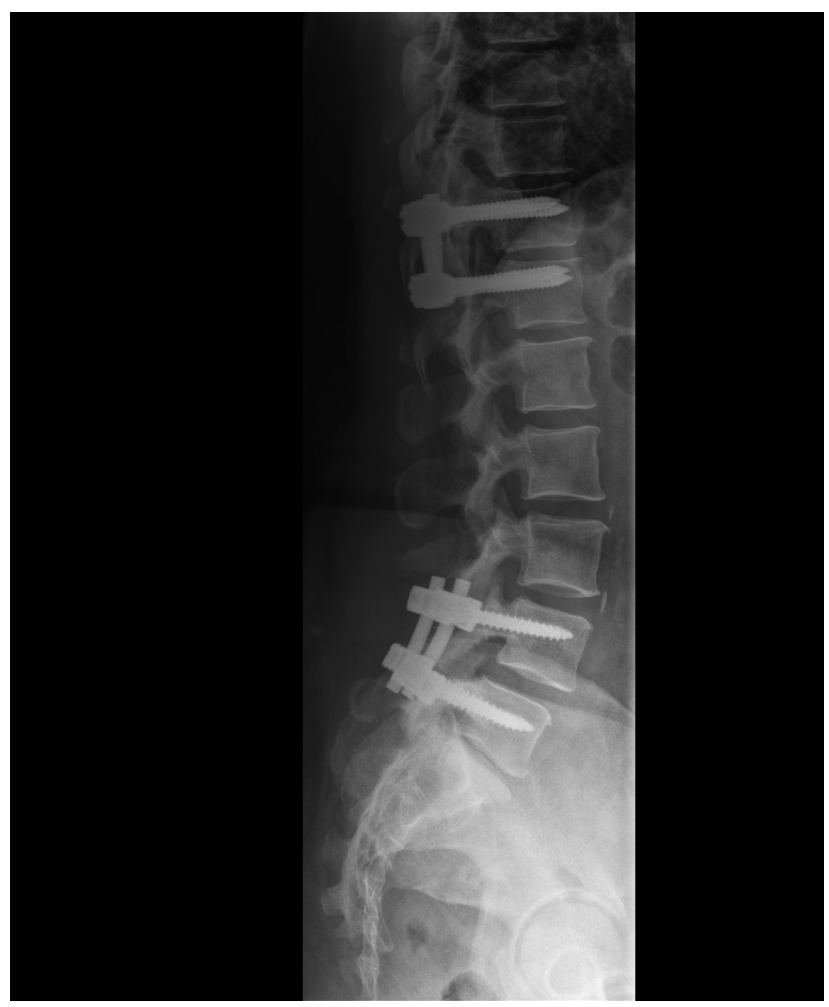

Fig. 4. Post-operative plain film lateral radiograph demonstrating posterior instrumented fusion at vertebral levels T11/12 and L4/5. 
the patient is still muscle relaxed leaving the neck vulnerable to hyperextension and the shoulders prone to dislocation or joint injury.

Thoracic disc herniation accounts for $0.25-0.75 \%$ of all symptomatic herniated discs and trauma is involved in up to $50 \%$ of these cases. ${ }^{1}$ They occur most commonly in the third, fourth and fifth decades of life with approximately $75 \%$ of herniation occurring below the T8 level and the vast majority occurring at T11/12 due to hypermobility at this site. ${ }^{2}$ Clinical features include myelopathy, non-myotomal motor weakness distal to the lesion and pain radiating in a band-like manner over the relevant dermatomal region. ${ }^{1,2}$ Making the diagnosis may be challenging as referred pain occurring over the trunk may mimic visceral pathology hence a thorough history, examination and relevant imaging is vital. Thoracic disc herniation is not a documented complication of the prone position. A thorough literature review was performed and demonstrated no previous reports of thoracic disc herniation associated with the prone position in spinal surgery.

Numerous other neurological complications exist with the prone position in spinal surgery however.

Postoperative brachial plexus and peripheral nerve injuries are amongst the most common neurological complications associated with the prone position. These patients present with acute neuropraxia as the brachial plexus is fixed at the cervical vertebrae and axillary fascia which thereby increases the risk of traction injuries. ${ }^{3,4}$ Additionally, the brachial plexus traverses the clavicle, first rib, and humeral head. The position of these osseous structures relative to the brachial plexus may stretch or compress the neural elements, resulting in ischemia. The risk is further increased by arm abduction of greater than 90 degrees. ${ }^{5}$ The majority of patients with such neuropraxias' recover from brachial plexus injuries, but the recovery is not always complete. ${ }^{5,6}$

Peripheral nerve injuries have also been implicated with the prone position during spinal surgery with the commonest nerve involved being the ulnar nerve. ${ }^{6}$ Injury may occur due to either direct pressure beneath the medial epicondyle of the humerus at the elbow, malposition of the blood pressure cuff, flexion of the elbow greater than 90 degrees, or due to sudden accidental change in the position of the arm such as the arm falling off the arm board. Other peripheral nerves that may be compressed include the lateral femoral cutaneous nerve ( $\mathrm{LFCN})$. This results in meralgia paraesthetica, a condition characterized by tingling, numbness and pain of the lateral thigh and has been attributed to the direct compression of the LFCN after placement of pelvic bolsters near the anterior superior iliac spine. ${ }^{7}$

Spinal cord infarction is a rare complication. This has been reported extensively in patients with chest wall deformities and skeletal dysplasia. ${ }^{7,8}$ Previous reports have suggested that the sudden reduction in cardiac output associated with prone positioning is exacerbated in patients with chest wall deformities such as pectus excavatum. ${ }^{910}$ This can be compounded further in hypotensive and hypovolemic states.

Other rare complications include cervical spinal cord compression secondary to acute cervical disc herniation or damage from pre-existing canal stenosis secondary to spondylosis. ${ }^{11}$ This usually results from a combination of prone positioning, neck extension during endotracheal intubation and loss of muscle tone during administration of muscle relaxants leading to neck hypermobility.

The patient described above developed sudden paraparesis after surgery with a T11 sensory level due to an acute herniated thoracic disc. Potential causes of this include hypermobility of the thoracolumbar spine during proning exacerbated by loss of muscle tone during the anaesthetic induction. ${ }^{12}$ Careful positioning during placement of the patient in the prone position, premedication in the form of benzodiazapines to minimize anxiety and agitation, smooth anaesthetic induction and avoidance of judicious doses of muscle relaxants remain the mainstay in prevention of mechanical injuries during proning. ${ }^{13}$ Regular and thorough communication between the surgical and anaesthetic teams also makes the proning process safer. Excessive hip flexion and hence loss of lumbar lordosis during prone placement on the Wilson frame may also contribute to disc prolapse and should be avoided. A Jackson table may negate this 
risk.

A full neurological examination remains paramount after any major surgery involving the spine and neural structures. This must be done as early as realistically possible. One logically tends to focus on the surgical site once neurological deterioration occurs in the immediate post-operative period, but this case highlights where a thorough examination localised the pathology to a level which is regularly cut-off on routine lumbar MRI imaging and almost certainly would have been missed if not specifically targeted during imaging. Where time is of the essence in acute spinal cord compression, this could have had devastating permanent consequence.

\section{References}

1. Alexianu D, Skolnick ET, Pinto AC, Ohkawa S, Roye DP, Solowiejczyk DE, Hyman JE, Sun LS. Severe hypotension in the prone position in a child with neurofibromatosis, scoliosis and pectus excavatum presenting for posterior spinal fusion. Anesth Analg. 2004;98:334-335.

2. Bafus BT, Chiravuri D, van der Velde ME, Chu BI, Hirshl R, Farley FA. Severe hypotension associated with the prone position in a child with scoliosis and pectus excavatum undergoing posterior spinal fusion. J Spinal Disord Tech. 2008;21:451-454.

3. Chen SH, Hui YL, Yu CM, Niu CC, Lui PW. Paraplegia by acute cervical disc protrusion after lumbar spine surgery. Chang Gung Med J. 2005;28:254-257.

4. Chung I, Glow JA, Dimopoulos V, Walid MS, Smisson HF, Johnston KW, Robinson JS, Grigorian AA. Upper-limb somatosensory evoked potential monitoring in lumbosacral spine surgery: a prognostic marker for position-related ulnar nerve injury. Spine 2009;9:287-295.

5. Daniels AH, Deodhar AA, Hart RA. Traumatic spondyloptosis resulting from high-energy trauma concurrent with a tonic-clonic seizure. Spine 2009;9:e1-e4.

6. Deem S, Shapiro HM, Marshall LF. Quadriplegia in a patient with cervical spondylosis after thora- columbar surgery in the prone position. Anesthesiology 1991;75: 527-8.

7. Johann JL, Martin O, Alois O, Stephan F. Quadriplegia after lumbar disc surgery: a case report. Spine 1996;21:1932-5.

8. Sherman CE, Rose PS, Pierce LL, Yaszemski MJ, Sim FH. Prospective assessment of patient morbidity from prone sacral positioning. J Neurosurg Spine 2012;16:51-56.

9. Tong CK, Chen JC, Cochrane DD. Spinal cord infarction remote from maximal compression in a patient with Morquio syndrome. J Neurosurg Pediatr. 2012;9:608-612.

10. Uribe JS, Kolla J, Omar H, Dakwar E, Abel N, Mangar D, Camporesi E. Brachial plexus injury following spinal surgery. J Neurosurg Spine 2010;13:552-558.

11. Whitcomb DC, Martin SP, Schoen RE, Jho HD. Chronic abdominal pain caused by thoracic disk herniation. Am J Gastroenterol. 1995;90:835-7.

12. Wilkes LL. Paraplegia from operation position and spinal stenosis in non-spinal surgery: a case report. J Neurol Surg 1980;146:148-9.

13. Xiong Y, Lachmann E, Marini S, Nagler W. Thoracic disk herniation presenting as abdominal and pelvic pain: A case report. Arch Phys Med Rehabil 2001;82:1142-4.

\section{Disclosures \& COI}

The authors declare no relevant disclosures or conflicts of interest.

\section{Corresponding Author}

Dr Ameya S. Kamat, Division of Neurosurgery, Tygerberg Hospital, Stellenbosch University, Francie Van Zijl Drive, Parow, Cape Town, South Africa.amskam@gmail.com.

Published 22 November 2016. This manuscript is generously published free of charge by ISASS, the International Society for the Advancement of Spine Surgery. Copyright @ 2017 ISASS. To see more or order reprints or permissions, see http://ijssurgery.com. 